\title{
Inclusion complexes of cyclomaltooligosaccharides (cyclodextrins) with melatonin in solid phase
}

\author{
David Bongiorno, ${ }^{a}$ Leopoldo Ceraulo, ${ }^{* a}$ Mirella Ferrugia,${ }^{a}$ Felice Filizzola, ${ }^{a}$ \\ Angela Ruggirello, ${ }^{b}$ and Vincenzo Turco Liveri ${ }^{b}$ \\ ${ }^{a}$ Dipartimento di Chimica e Tecnologie Farmaceutiche, Università di Palermo, via Archirafi \\ n.32 I-90123 Palermo, Italy and ${ }^{b}$ Dipartimento di Chimica-Fisica, Università di Palermo, \\ Viale delle Scienze, Parco d'Orleans II I-90128 Palermo, Italy \\ E-mail: lceraulo@unipa.it, turco@unipa.it
}

\begin{abstract}
Fourier transform infrared spectrometry (FT-IR) and X-Ray diffraction (XRD) investigations were carried out on MLT plus $\alpha-, \beta$ - and $\gamma-\mathrm{CD}$ physical mixtures and lyophilized or crystalline $\mathrm{MLT} / \alpha-, \beta-, \gamma-\mathrm{CD}$ complexes. Inclusion complexes formation between MLT and cyclodextrins in solid phase has been emphasized by the significant differences between IR and XRD spectra of physical mixtures with respect to those of the complexes. The structure of MLT CDs complexes in the solid state as well as the biochemical and pharmaceutical implications are discussed.
\end{abstract}

Keywords: Melatonin, cyclodextrins, inclusion complexes, solid phase, FT-IR, XRD

\section{Introduction}

Melatonin (MLT), is a quite ubiquitous molecule being present in practically all living organisms ranging from protista to reptiles and mammals. In humans, it is secreted during night by the pineal gland and it is involved in the regulation of various neuroendocrine physiologic cellular processes as well as several neural effectors ${ }^{1}$ almost connected with the circadian variation of daylight/night alternation and thus regulating sleep and seasonal reproduction cycles ${ }^{2}$. Melatonin has also recently come to footlights because it is the unique hormone which, being a strong antioxidant, can act as powerful inhibiter of free radicals, ${ }^{3}$ scavenger of hydroxyl radicals, ${ }^{4}$ lipoperoxyl radicals ${ }^{5,6}$ and nitric oxide. ${ }^{7,8}$

At present, therapeutic applications of melatonin include circadian rhythm disorders, ${ }^{2}$ cancer, ${ }^{9-11}$ AIDS, ${ }^{12}$ Alzheimer disease, ${ }^{13,14}$ cataract $^{15}$ and cardiac disease. ${ }^{16}$ Further, for its relevant biological properties that are also associated with an extremely low toxicity, melatonin could act as a drug for a number of other diseases. ${ }^{17,18}$ 
For the properties above described, MLT finds a wide range of application in the pharmaceutical field. However its employment is limited by a low water solubility $(0,002$ $\mathrm{mol} / \mathrm{kg})^{19}$ and by its relative sensitivity to light.

Previous studies have been conducted on MLT and CDs in gas and solution phase. ${ }^{19,20}$ Solid state interaction between MLT and CDs, have not been previously reported except for some patents $^{21-23}$ that however deal with natural and derivatized CDs complex only and do not give any structural information about the complexes obtained

Being an amphiphilic ${ }^{24}$ molecule, melatonin shows a marked tendency to locate, by means of non-covalent interactions, at the interface between polar and apolar regions. ${ }^{25}$ MLT location among hydrophobic chains would justify protective action of lipids from the attack of free radicals originated in the interior of membrane. Such observations are the basis of previous studies on MLT inclusion in $\alpha-\beta$ - and $\gamma$ - cyclodextrin (CD) apolar cavities in aqueous solutions $^{19}$ and gas phase. $^{20}$ These studies evidenced MLT behavior in systems having a hydrophobic cavity surrounded by a hydrophilic region. Cyclodextrins are useful to mimic hydrophobic cavities present in various biological systems. Besides, they are able to host molecules having suitable sizes, through the formation of non-covalent bonds. ${ }^{26,27}$ These inclusion complexes are of considerable scientific and technological interest. In fact through alcoholic residuals present in the external part of complex it is possible to solubilize in polar solvent even non polar molecules. Substantial improvement of various parameters including stability, bioavailability, release control and palatability are also achieved. ${ }^{28}$ In fact CDs are quite stable molecules made up by glucosidic residues which model a hydrophobic cavity, they resist to alkaline solutions but are sensible to strong acid solutions, which determine the ring opening. Generally CDs are useful to enhance the solubility of drugs in water and their clearance, to lower local and systemic toxicity and to act as artificial carrier for endogenous and exogenous lipophilic substances. In particular, $\beta$-cyclodextrin has been approved by the Food and Drug Administration and by European Community as alimentary low-cost additive.

Inclusion complexes of various biologically active indole derivatives, such as indomethacin, ${ }^{29}$ tryptophan, ${ }^{30}$ methoxytryptamine $^{31}$ and melatonin ${ }^{19,}{ }^{20}$ have been previously investigated as well as the interactions of solid cyclodextrins with compounds of pharmaceutical interest. The aim of the present study is to ascertain the formation and stability of inclusion complexes of MLT with natural cyclodextrins in the solid phase and to investigate confinement effects of MLT in hydrophobic cavities simulating biological receptors.

\section{Results and Discussion}

FT-IR analysis of MLT/ $\alpha-, \beta-, \gamma-C D$ physical mixtures and complexes. FT-IR technique has been chosen to detect complex formation in solid phase and to emphasize the functional groups responsible of the solid MLT/CD complex stability. It has previously evidenced ${ }^{19}$ that the interactions established between MLT and CDs in aqueous phase are mainly hydrophobic, but 
also some polar groups emerging from the cavity contribute to the complex stability, probably by the formation of hydrogen bonds, with outer rim hydroxyl groups.

A comparison between FT-IR spectra of MLT, $\alpha-, \beta-, \gamma-$-cyclodextrins, physical mixtures and inclusion complexes, evidences some significant changes in the shape and position of the absorbance bands of MLT and CDs functional groups.

In particular, for pure MLT as $\mathrm{KBr}$ solid dispersion, noteworthy differences have been observed respect to the IR spectrum of $\mathrm{MLT} \mathrm{CH}_{2} \mathrm{Cl}_{2}$ dilute solution, being principal absorbance signals shifted toward higher wavenumbers (Table 1).

Table 1. Comparison of the principal differences between MLT at solid state and $\mathrm{MLT} \mathrm{CH}_{2} \mathrm{Cl}_{2}$ in dilute solution signals

\begin{tabular}{ccc}
\hline & MLT Crystals signals & MLT CH $\mathrm{Cl}_{2}$ Solution signals \\
\hline NH stretching & $3284-3305 \mathrm{~cm}^{-1}$ & $3490-3460 \mathrm{~cm}^{-1}$ \\
$\mathrm{CO}$ double bond stretching & $1627 \mathrm{~cm}^{-1}$ (twin band) & $1670 \mathrm{~cm}^{-1}$ (single convoluted band) \\
$\mathrm{CH}=\mathrm{CH}$ indole stretching & $1588 \mathrm{~cm}^{-1}$ & $1588 \mathrm{~cm}^{-1}$ \\
$\mathrm{NH}-\mathrm{CO}$ bending & $1556 \mathrm{~cm}^{-1}$ & $1520 \mathrm{~cm}^{-1}$ \\
$\mathrm{C}-\mathrm{O}-\mathrm{CH}_{3}$ bending & $1213 \mathrm{~cm}^{-1}$ & $1213 \mathrm{~cm}^{-1}$ \\
\hline
\end{tabular}

Polar groups, as $\mathrm{CO}$ and indolic and amidic $\mathrm{NH}$, capable to form strong hydrogen bonds, are those mainly implicated in the frequency signal shift with respect to the dilute solution in $\mathrm{CH}_{2} \mathrm{Cl}_{2}$. This is an indication that in solid phase both amidic $\mathrm{NH}$ and indolic amino groups as well as $\mathrm{CO}$ are involved in intermolecular hydrogen bonding.

Superimposed e FT-IR spectra of $\alpha, \beta, \gamma$ cyclodextrins solid phas are shown in Figure 1.

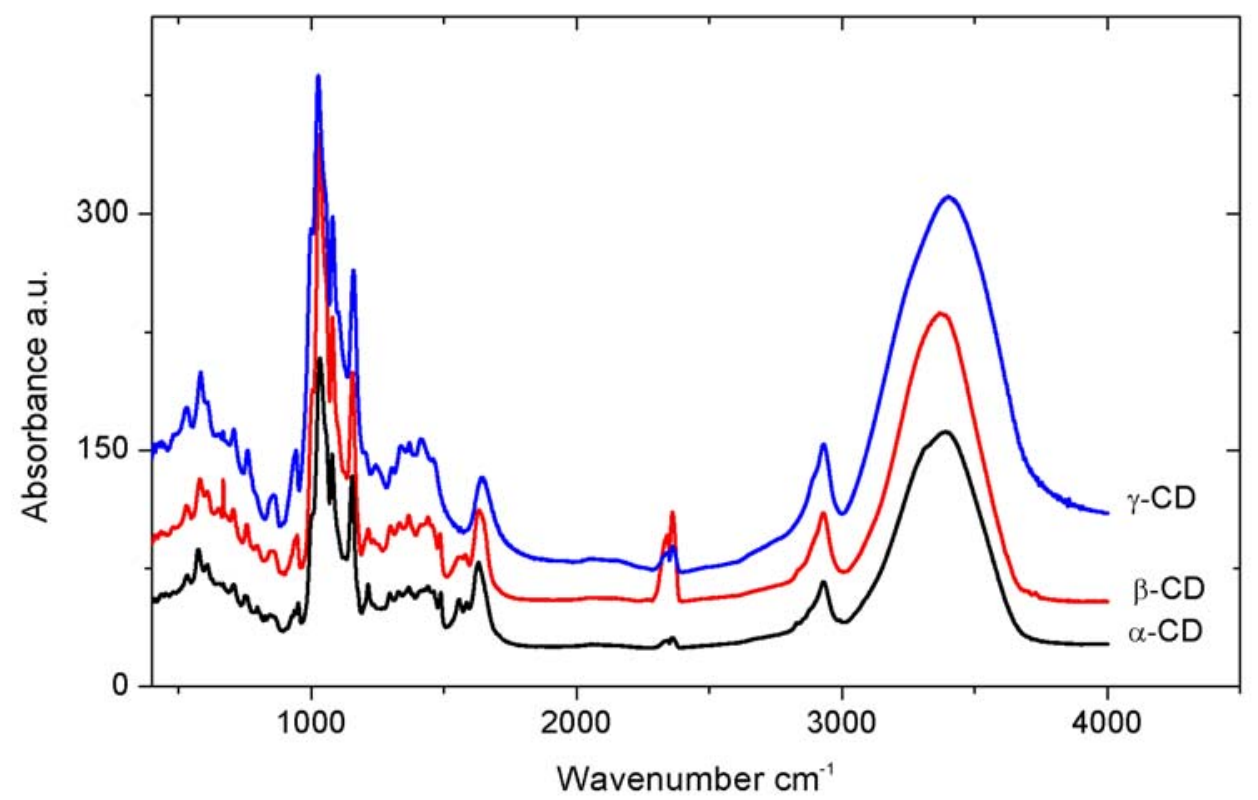

Figure 1. Solid phase natural cyclodextrin FT-IR spectra overlays. 
The most interesting signals are:

- Wide band at 3300-3600 $\mathrm{cm}^{-1}$ due to $\mathrm{OH}$ bonds stretching

- A strong and complex band at $1000-1260 \mathrm{~cm}^{-1}$ due to C-O- bonds stretching

The observation of the figure 2 that shows the superposition of FT-IR spectra of MLT and $\beta$-CD as pure substances, and both of $\beta-\mathrm{CD} / \mathrm{MLT}$ as simple physical mixture and as complex evidences some noteworthy differences between the spectra. The most evident property is shown by the 1:1 physical mixture spectrum of $\beta-C D / M L T$ that is a complete superposition of the spectra of MLT and $\beta-C D$ spectra.

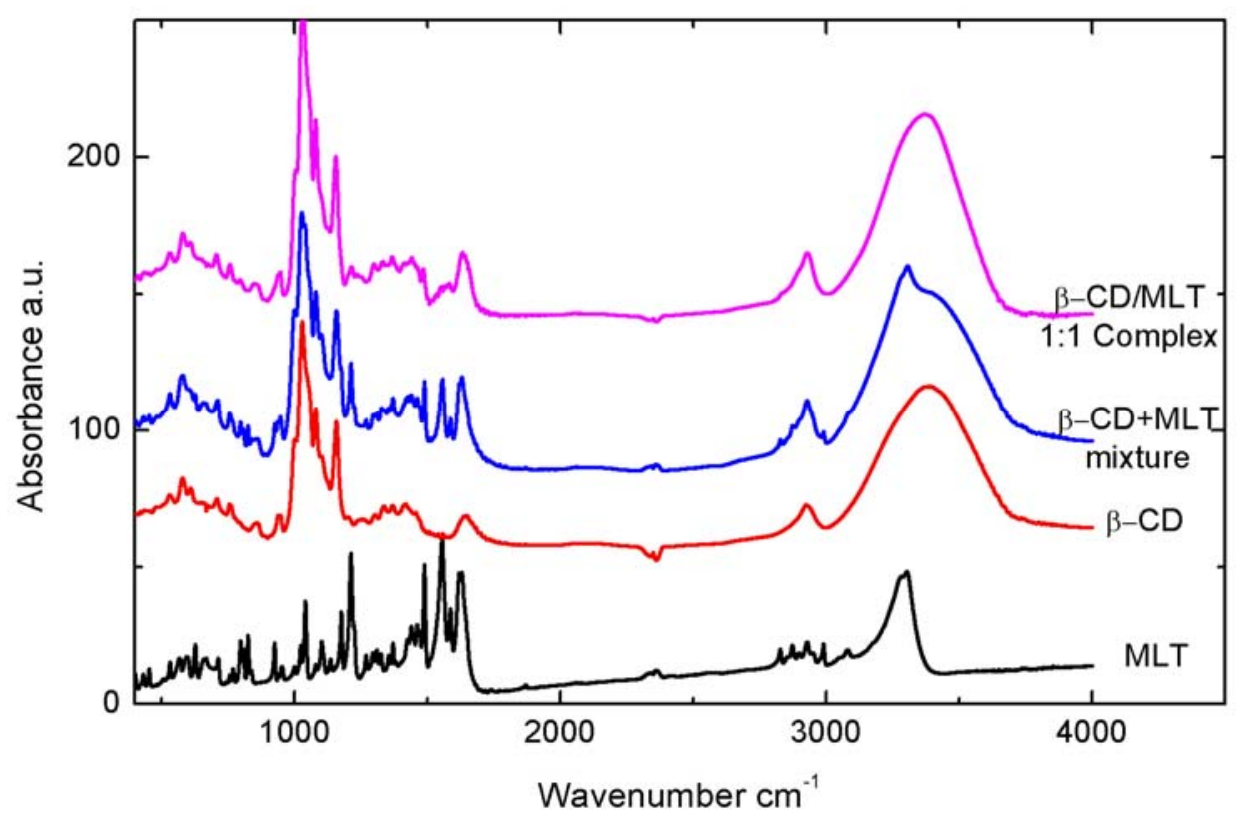

Figure 2. Comparison between FT-IR spectra of MLT, $\beta$-CD/MLT 1:1 mixture and $\beta$-CD/MLT $1: 1$ complex.

The spectrum of the solid 1:1 complex $\beta-\mathrm{CD} / \mathrm{MLT}$ is instead similar to that of pure $\beta-\mathrm{CD}$, being the signals due to MLT quite completely convoluted and suppressed by the $\beta$-CD signals. Even the most strong peak due to $\mathrm{NH}$ stretching is convoluted and shifted toward 3284-3305 $\mathrm{cm}^{-1}$.

Other differences are present in the fingerprint region, where most of the MLT characterizing signals are shifted and modified. In particular:

- (Amidic) carbonyl group CO stretching of MLT (twin peak at $1627 \mathrm{~cm}^{-1}$, Table 2), is still distinguishable in the physical mixture, but appears as single peak in the complex spectrum. This behaviour could be explained only admitting that the hydrogen bond involving the amidic $\mathrm{CO}$ is still maintained in the solid complex. However this implies that, while in the crystalline MLT hydrogen bonds are established between two MLT molecules, in the complex, a single MLT molecule should be inserted more or less deeply in the 
hydrophobic cavity of the cyclodextrin. So in the complex a new hydrogen bond is formed between MLT and CD and in particular between primary $\mathrm{OH}$ of the outer (wider) rim and amide $\mathrm{CO}$.

- the sharp signal at $1556 \mathrm{~cm}^{-1}$, due to amide group (Table 1, Table 2) drastically reduces its intensity and sharpness in the complex.

- $\mathrm{C}-\mathrm{OMe}$ stretching signal at $1216 \mathrm{~cm}^{-1}$ (Table 2) is also quite disappeared in the complex spectrum, while it is perfectly maintained in the physical mixture spectrum.

Table 2. Comparison of the principal differences between $\beta-\mathrm{CD}$ crystals signals, solid state, $\beta$ $\mathrm{CD} / \mathrm{MLT}$ complex signals and $\beta-\mathrm{CD}+\mathrm{MLT}$ mixture signals

\begin{tabular}{|c|c|c|c|c|c|c|}
\hline & $\begin{array}{c}\mathrm{OH} \\
\text { Stretching }\end{array}$ & $\begin{array}{c}\mathrm{C}-\mathrm{O}- \\
\text { Stretching }\end{array}$ & $\begin{array}{c}\text { NH } \\
\text { Stretching }\end{array}$ & $\mathrm{NHCO}$ & $\begin{array}{c}\mathrm{C}-\mathrm{OMe} \\
\text { Stretching }\end{array}$ & $\begin{array}{c}\mathrm{C}=\mathrm{O} \\
\text { Stretchi } \\
\text { ng }\end{array}$ \\
\hline $\begin{array}{c}\beta-C D \\
\text { Crystals } \\
\text { signals }\end{array}$ & $3391 \mathrm{~cm}^{-1}$ & $\begin{array}{c}1000-1260 \\
\mathrm{~cm}^{-1}\end{array}$ & - & - & - & - \\
\hline $\begin{array}{c}\beta-\mathrm{CD} / \mathrm{MLT} \\
\text { complex } \\
\text { signals }\end{array}$ & $3382 \mathrm{~cm}^{-1}$ & $\begin{array}{c}1000-1260 \\
\mathrm{~cm}^{-1}\end{array}$ & $\begin{array}{c}3382 \mathrm{~cm}^{-1} \\
\text { Convoluted }\end{array}$ & $\begin{array}{c}1553 \mathrm{~cm}^{-1} \\
\text { wide }\end{array}$ & - & $\begin{array}{l}1627 \\
\mathrm{~cm}^{-1} \\
\text { wide }\end{array}$ \\
\hline $\begin{array}{c}\beta-C D+M L T \\
\text { Mixture } \\
\text { signals }\end{array}$ & $3391 \mathrm{~cm}^{-1}$ & $\begin{array}{c}1000-1260 \\
\mathrm{~cm}^{-1}\end{array}$ & $3306 \mathrm{~cm}^{-1}$ & $\begin{array}{c}1556 \mathrm{~cm}^{-1} \\
\text { sharp }\end{array}$ & $1216 \mathrm{~cm}^{-1}$ & $\begin{array}{c}1627 \\
\mathrm{~cm}^{-1} \\
\text { Sharp } \\
\text { twin }\end{array}$ \\
\hline
\end{tabular}

All these findings reasonably confirm the formation of the inclusion complex between MLT and $\beta$-CD. In fact the comparison between physical mixture and complex evidences strong differences that can be explained considering that mainly resonance frequencies of the functional groups of MLT in the mixture are not changed, both in wavenumber and in probability due to the persistence of both species as crystals of $\beta$-CD and MLT each characterized by its own crystal structure maintained still intact. Instead the convolution and shifting of major peaks of MLT in the complex spectrum evidences a substantial variation of bond strength and length that obviously reflects on the IR absorbance resonance frequencies. The most interested signals are those due to the polar functional groups of MLT and $\beta-C D$, implying that in some extent, polar interaction can act as stabilising force in the complex formation. The quite complete disappearance of MLT signals is also a confirmation of the formation of an inclusion complex. In fact have been evidenced for some inclusion complexes ${ }^{32}$ a "shield" effect on the host molecule by CDs. This is probably due to dipole moment variation, in the complex structure that can be explained only considering that original pure substances crystal structure have been quite completely rearranged in the complex structure. Even if not directly evident by the single signal shifting and absorbance variation, a further information can be obtained by the whole complex 
spectrum, widely similar to that of the pure $\beta$-CD: the final crystal structure should be at least similar to that of $\beta$-CD implying that the MLT should be included and not interposed between $\beta$ CD molecules.

Hydration effect on measures have been also investigated repeating experiments, on exposing in the oven $\left(120^{\circ}\right)$ to silica gel for variable times the complex obtained. Only minor spectra variations have been evidenced.

Similar results have been obtained from MLT/ $\alpha-C D$ (Figure 3) and MLT/ $\gamma-C D$ solid phase complexes (Figure 4).

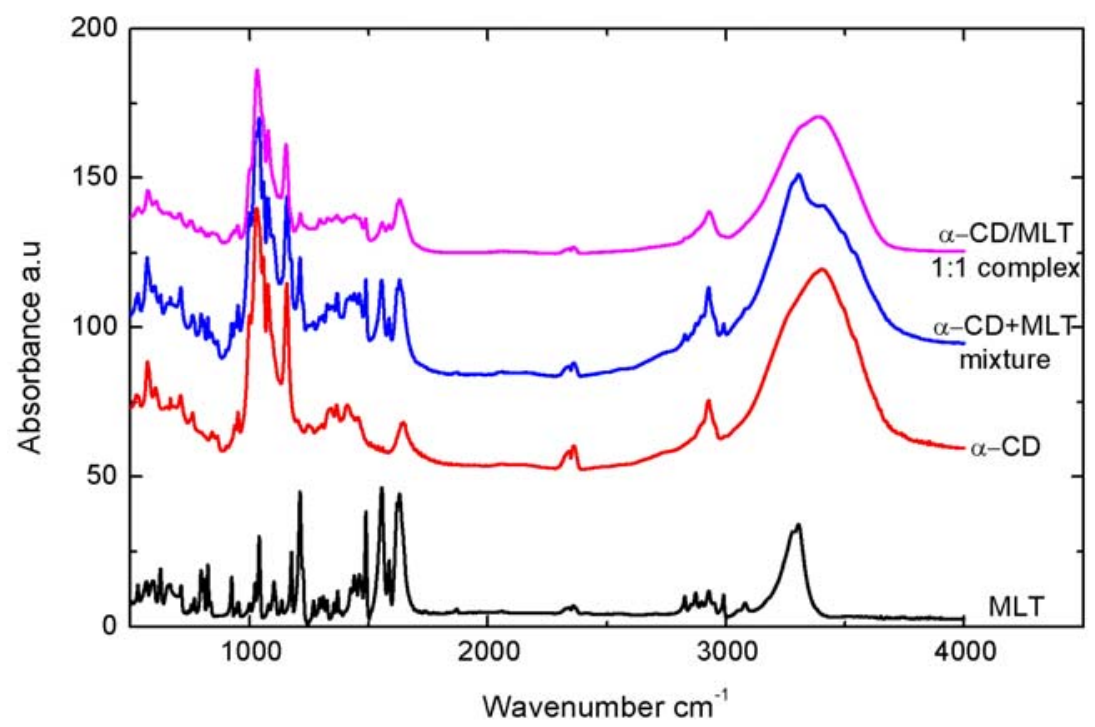

Figure 3. Comparison between FT-IR spectra of MLT, $\alpha-\mathrm{CD}, \alpha-\mathrm{CD} / \mathrm{MLT}$ mixture and 1:1 $\alpha-$ CD/MLT complex.

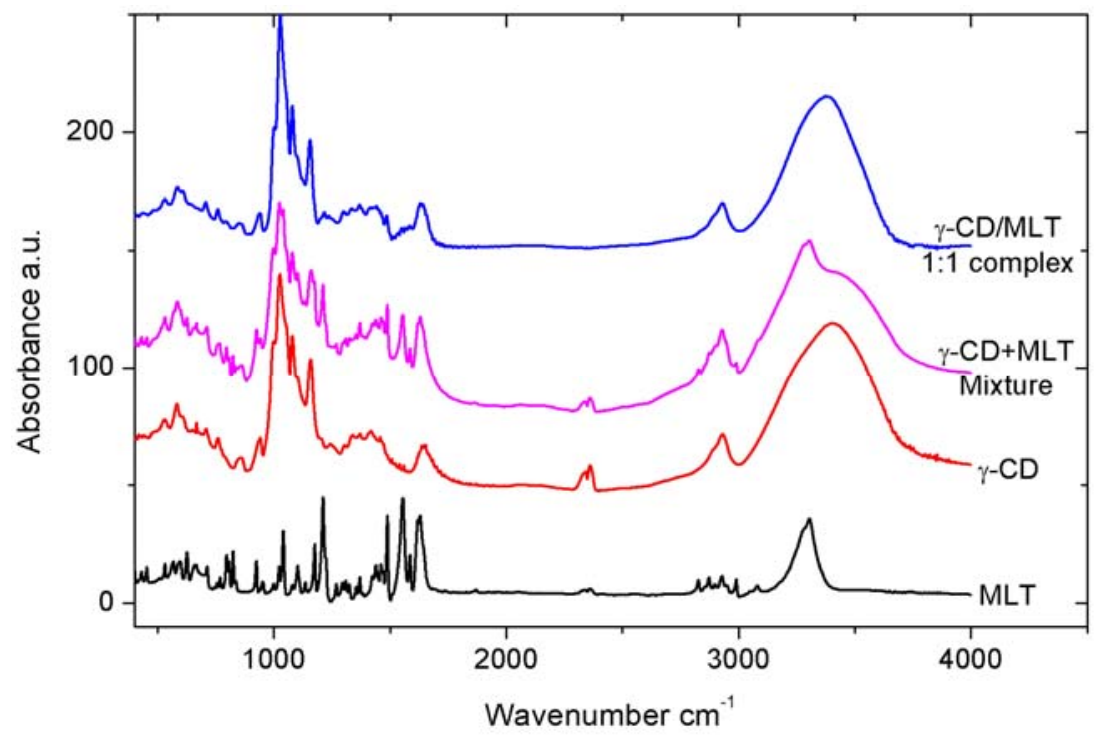

Figure 4. Comparison between FT-IR spectra of MLT, $\gamma-\mathrm{CD}, \gamma-\mathrm{CD} / \mathrm{MLT}$ mixture and 1:1 $\gamma-$ CD/MLT complex. 
In fact band shift and shape modification of the same diagnostic signals previously described can be observed in the spectra of both the complexes. Shielding effect due to CDs as well as the same general pattern of the spectra that are closely related to that of the pure CDs confirm that inclusion complexes have been obtained.

Accordingly to previous calorimetric data on solution phase complex, that allowed the determination of enthalpy, entropy and free energy and accordingly to ${ }^{1} \mathrm{H}-\mathrm{NMR} 2 \mathrm{D}-\mathrm{ROESY}$ experiments, ${ }^{19}$ FT-IR data obtained in this investigation can be used to suggest the formation of inclusion complexes between MLT and CDs (Figure 5). The complex shape should remain even in the solid phase the same that have been previously described, with apolar interaction that also represent a strong cohesive force. But in the solid phase some additional hydrophilic non covalent interaction between CDs ring and MLT have been evidenced, that involve $\mathrm{NH}$ and $\mathrm{CO}$ groups of MLT and OH groups of CDs, and contribute to the stability of the whole complex.
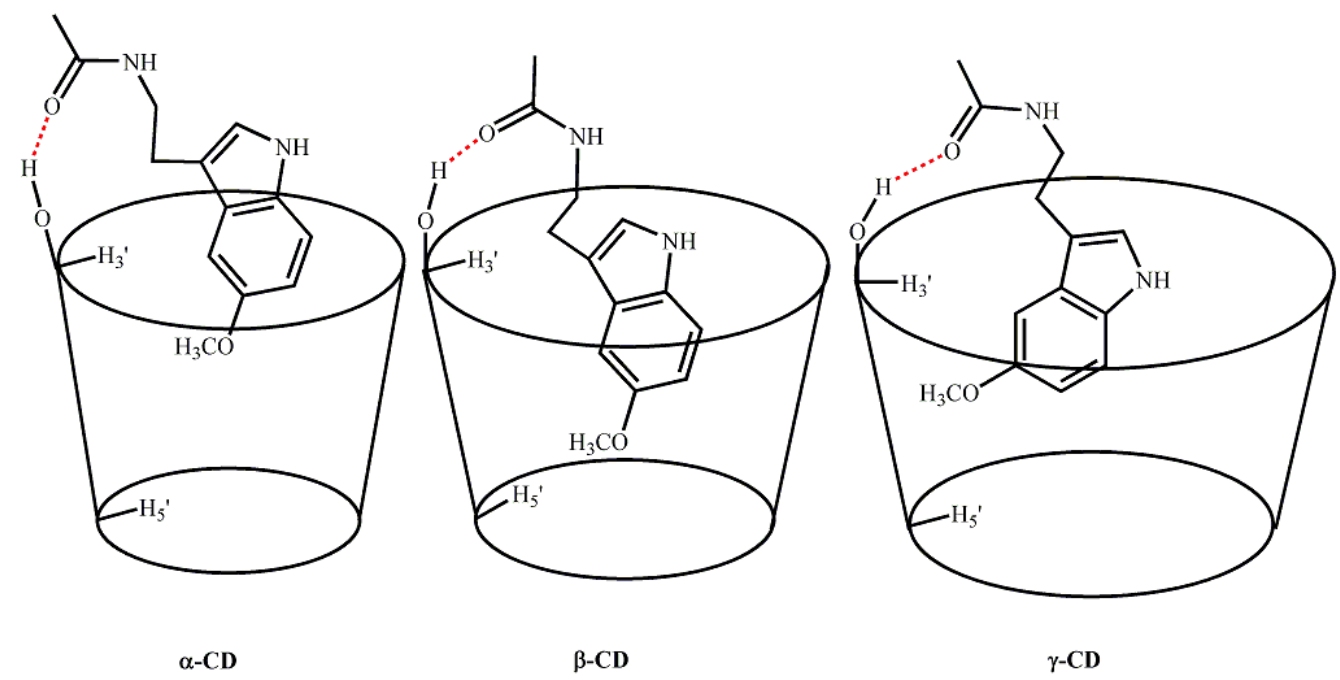

Figure 5. Representation of the various inclusion modality of MLT in the investigated CDs.

Wide angle $X$-ray scattering analysis. Further information upon MLT/ $\alpha-, \beta-, \gamma$-CD complexes have been achieved by wide angle X-ray scattering.

In the case of MLT/ $\beta$-CD complex as shown in figure $6 \mathrm{~A}$ and $6 \mathrm{~B}$, both spectra of the complexes investigated $\beta-\mathrm{CD} / \mathrm{MLT}$ in the $1: 1$ e $2: 1$ ratios evidenced variation on the crystal structure that can justify the complex formation in the solid state.

In particular the small auxiliary peaks with respect to $\beta-C D$ and MLT diffraction patterns, at $6.25^{\circ}$, implies a variation of intermolecular distances within the crystal lattice (Figure $6 \mathrm{~A}$ ) as well as the complete disappearance of the MLT peak at $16^{\circ}$ (Figure $6 \mathrm{~B}$ ) points out that a new crystal structure have been obtained. 


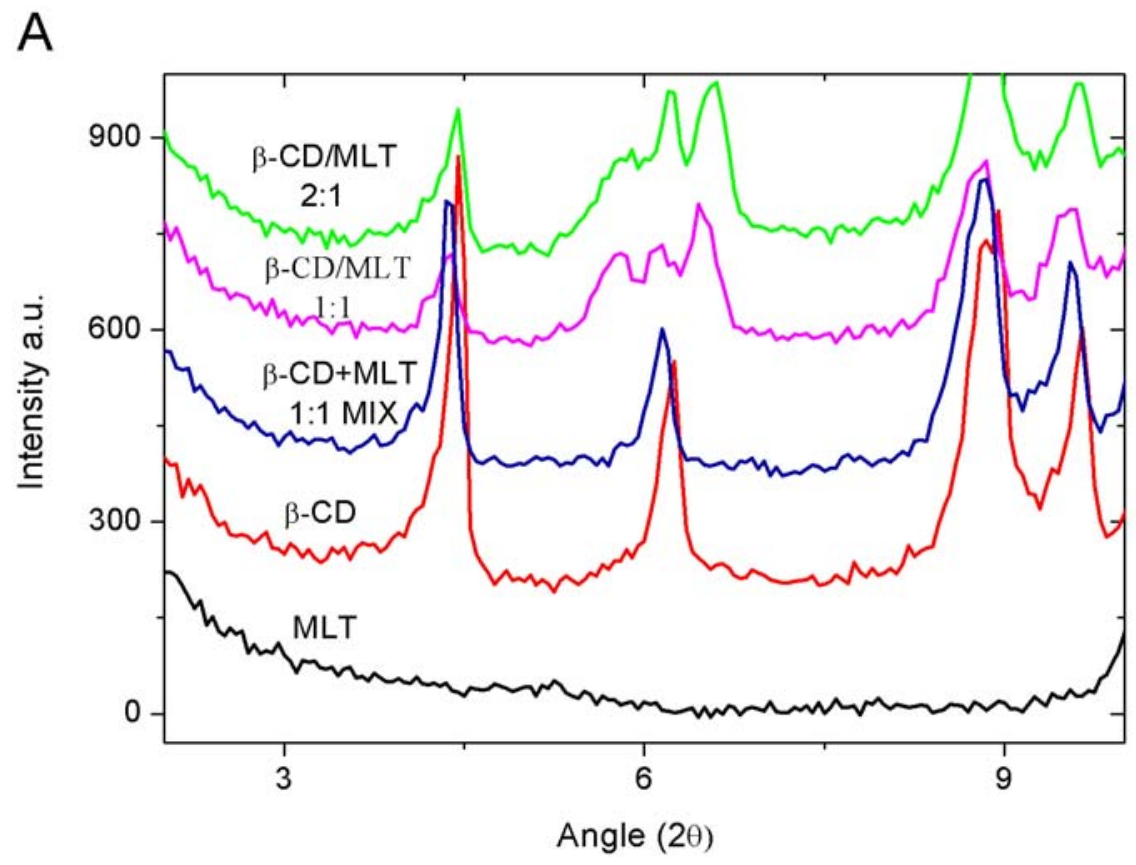

B

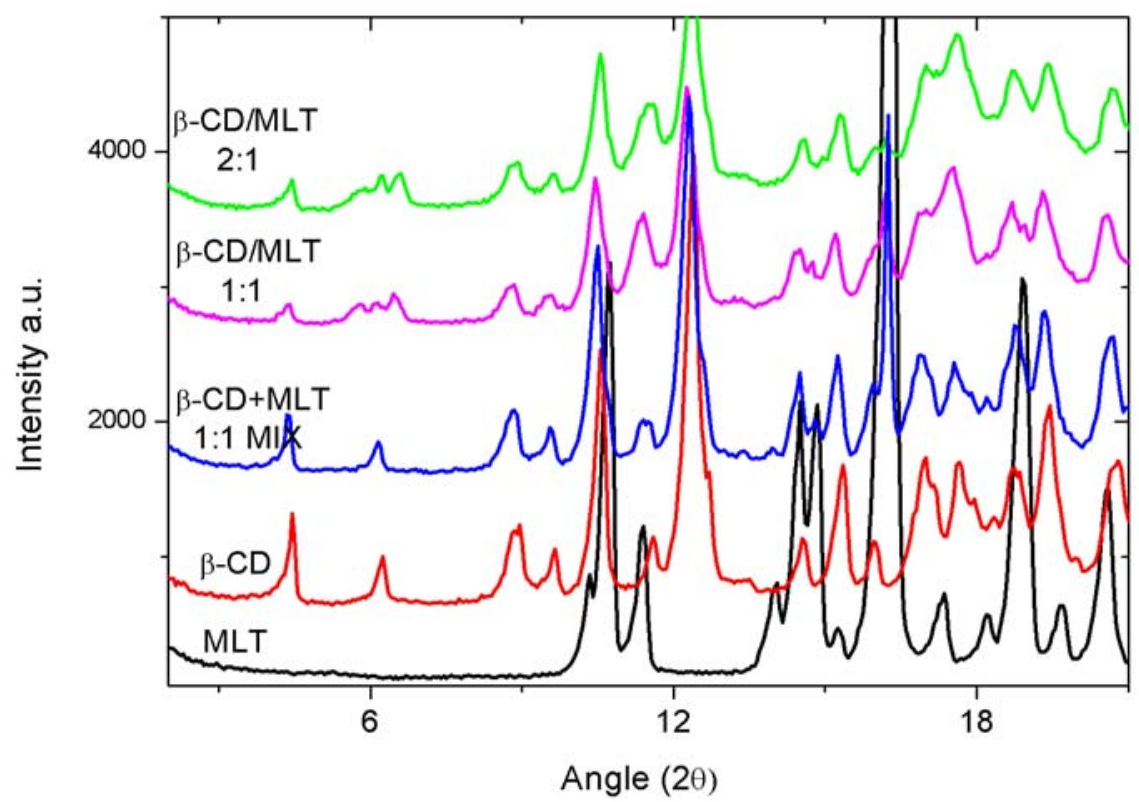

Figure 6. A: X-Ray diffraction patterns of MLT, $\beta$-CD, $\beta$-CD/MLT 1:1 mixture, $\beta$-CD/MLT 2:1, $\beta$-CD/MLT 1:1 in the range between $2^{\circ}$ e $10^{\circ}$ and B: X-ray powder diffraction patterns of MLT, $\beta$-CD, $\beta$-CD/MLT 1:1, $\beta$-CD/MLT 2:1, $\beta$-CD/MLT 1:1 physical mixtures and complexes.

A careful analysis of the spectra suggests that the 1:1 MLT/ $\beta-C D$ complex shows small amount of pure MLT, that becomes negligible in the 2:1 complex. In the spectrum of the mixture between $\beta-C D$ and MLT instead is evident a strong presence of uncomplexed MLT. A general 
observation of the spectra, largely similar to that of $\beta$-CDs and completely different with respect to MLT, suggests also that crystal structure of the complexes should be similar to that described for $\beta-C D$, in fact similar signals both at low and wide angle indicate that intermolecular, more likely and interatomical distances, in lesser extent are quite super imposable. This aspect also implies that MLT should be included and not interposed between CD molecules. This latter case would imply a more substantial variation of complex crystal signals to respect with pure $\beta$-CD.

The analysis of the diffraction patterns of $\alpha-\mathrm{CD} / \mathrm{MLT}$ (Figure 7) complex and of pure crystalline substances shows a behaviour similar to that described for $\beta$-CD/MLT complexes. Even in this case have been investigated both complexes with 1:1 and 2:1 $\alpha$-CD/MLT ratios, and again slight but diagnostic variation of the X-ray spectra evidenced that new structures have been generated, different from those of the pure substances.

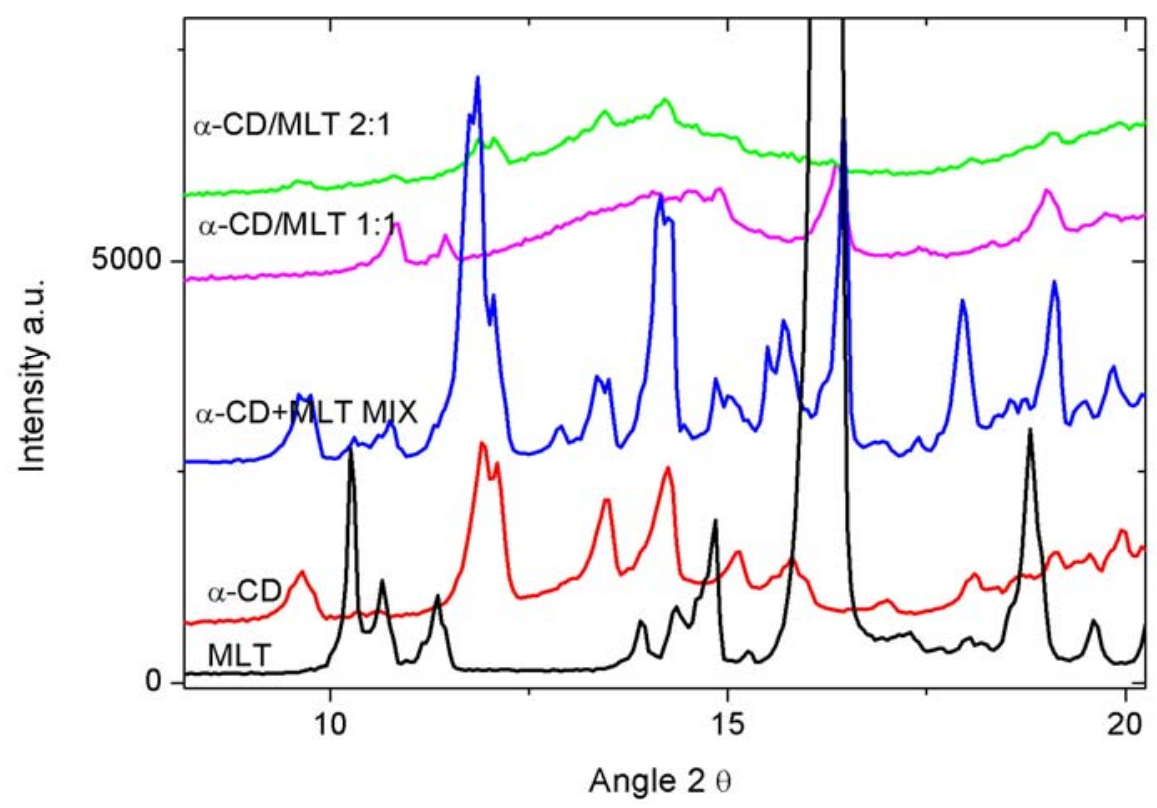

Figure 7. X-ray powder diffraction patterns of MLT, $\alpha-C D, \alpha-C D / M L T ~ 1: 1, \alpha-C D / M L T ~ 2: 1, \alpha$ -CD/MLT 1:1 physical mixtures and complexes.

The most interesting variation is the lowering in complexes and physical mixture of the $16^{\circ}$ peak diagnostic for the presence of pure MLT crystals. The peak is lowered but detectable in the physical mixture of MLT and $\alpha-C D$, is even lower but still present in the $\alpha$-CD/MLT 1:1 complex, while is practically absent in the spectrum of the $\alpha$-CD/MLT 2:1 complex. This finding suggests that the stoichiometry $1: 1$ is not sufficient to entirely complex the MLT, while a complete inclusion is achieved by increasing the relative amount (excess) of $\alpha-C D$ and besides that the formation of $\alpha-C D / M L T$ complexes can be made in some extent by simple kneading. This finding is also confirmed by the loss and shift of some other MLT diagnostic peaks at $10,25^{\circ}$ and $18,8^{\circ}$ respectively. As for $\beta-\mathrm{CD} / \mathrm{MLT}$ the aspect of the spectra of the complexes and above all the strict similarity with pure $\alpha-C D$ ones suggests the inclusion of the molecule in the 
hydrophobic cavity of $\alpha-C D$. Besides, the low peak intensities of the $\alpha-C D / M L T$ complexes suggest that the structural perturbation due to the MLT inclusion involves a marked loss in crystallinity of $\alpha-C D$ which is, for steric reasons, more significant than that of $\beta$ - and $\gamma-C D$.

The diffractograms obtained from $\gamma$-CD and MLT as pure substances (Figure 8), as mixture and as complex clearly reveal substantial differences between the pure substances ad final complex obtained. Noteworthy is the fact that with this kind of cyclodextrin the complete disappearance of the peak at $16^{\circ}$ (diagnostic for crystalline MLT) have been achieved with the stoichiometry 1:1. The substantial difference between complex and physical mixture, that perhaps contains itself inclusion complexes formed during kneading, confirm the presence of a new quite crystalline form adduct.

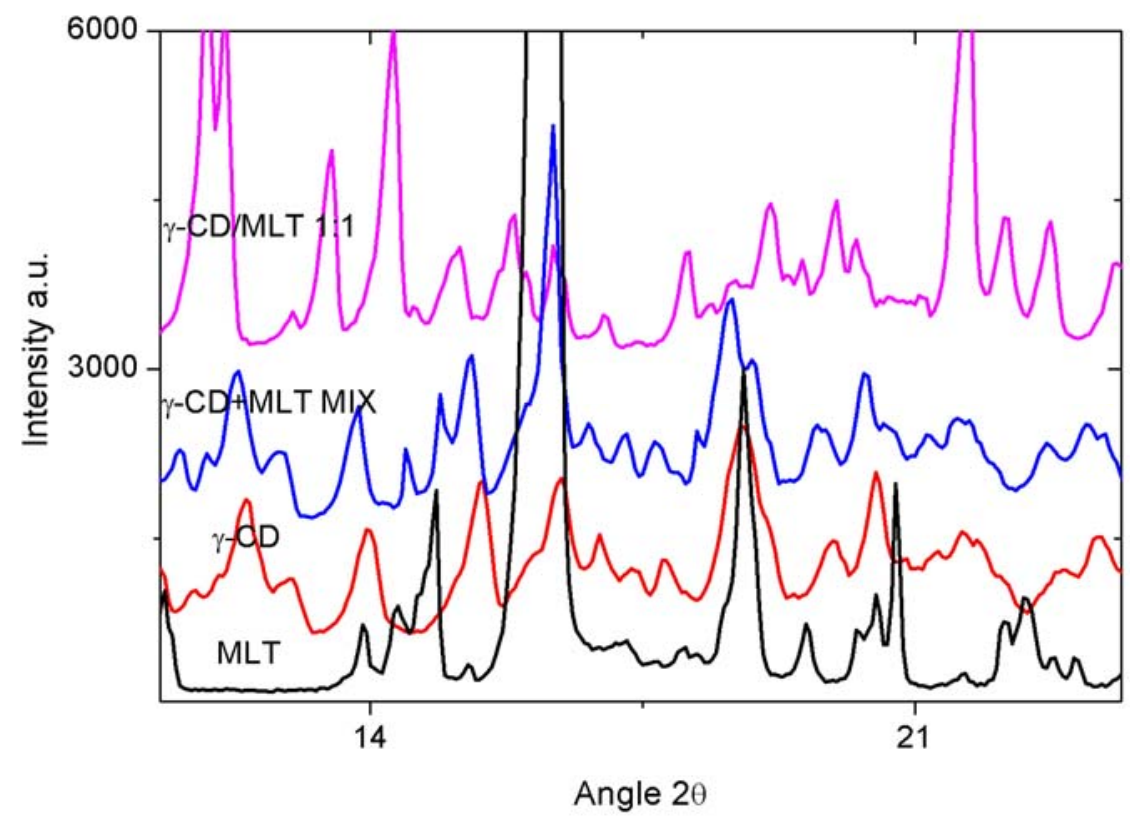

Figure 8. X-ray powder diffraction patterns of MLT, $\gamma$-CD, $\gamma$-CD/MLT 1:1, $\gamma$-CD/MLT 2:1, $\gamma$ CD/MLT 1:1 physical mixtures and complexes.

A more critic examination of the diffractrogram that lacks of many sharp peaks, and finally is fundamentally different from other species, could account for a not perfectly crystallized adduct, as well as the presence of more complicated inclusion complex formation. Lack of the peak at $16^{\circ}$ does not completely rule out the maintaining of two different crystalline species (MLT and $\gamma$-CD), however the lack of other MLT diagnostic peak does not support the presence of such crystals. Strong differences in the low angle region can be only justified by a consistent variation of the final crystal reticulum with respect to that of the pure $\gamma-\mathrm{CD}$, this could be due to a conformational variation induced by MLT on the cone-shaped $\gamma$-CD form that results in a different packaging of the crystals.

However an amorphous form, even in mixture with crystals cannot be excluded at this stage. 


\section{Conclusions}

In this work using FT-IR and X-Ray diffraction has been ascertained that MLT can form, even in the solid phase, non covalent complexes with natural CDs. In fact an evidence of inclusion complexes formation between MLT and cyclodextrins in solid phase has been shown by the considerable differences of IR spectra of physical mixture with respect to those of the complexes.

Complexes formation has been also studied through crystallographic investigation. Powder $\mathrm{X}$-ray diffraction patterns of the three inclusion complexes formed by MLT and $\alpha-\beta$ - and $\gamma$-CD, of mechanical mixture of the crystalline substances in the 1:1 ratio and of complexes formed through crystallization from solutions containing CDs and MLT in the 1:1 and 2:1 ratios respectively, evidence variations of the crystalline structure which also justify inclusion complex formation in solid state.

It is also worth to note that inclusion complexes formation between MLT and CD have been observed also in solution and gas phase and thus not limited to a particular phase or condition. It has previously described ${ }^{26}$ that cyclodextrin can be used as model to mimic hydrophobic sacks in membranes in cell, and this kind of interaction makes reasonable to suppose that in biological systems MLT could be localized preferentially in hydrophobic sacks present in cell membranes.

Similar results have been also achieved by analysis of MLT containing anhydrous micellar systems. ${ }^{33}$ These data can justify also the strong protection effect, almost against free radicals, of MLT on cell membranes, that have been reported. ${ }^{4-8}$

Infrared spectra on the solid complex demonstrated that in the formation of inclusion complexes an important contribution is due to polar bonds formation-modification, thus evidencing once more ${ }^{33}$ that MLT is preferentially localised in interfacial nano-districts, between polar and apolar domains. In these interfacial regions MLT can strongly act as protective agent.

\section{Experimental Section}

General Procedures. Melatonin (Aldrich St. Louis, MO, USA, 99.5\%), $\alpha, \beta, \gamma$-cyclodextrins (Fluka, Buchs, Switzerland, 99.5\%), water (Fluka, HPLC grade), potassium bromide (Fluka, 98\%), dichloromethane (J.T.Baker, Phillipsburg, NJ, USA, 99\%) were used without any further purification.

FT-IR spectra in solution were recorded with a Bruker (Karlsrue, Germany) IFS25 FT-IR spectrometer, using a cell equipped with $\mathrm{CaF}_{2}$ windows. For all measurements 100 scans in the $800-4000 \mathrm{~cm}^{-1}$ wavenumber range were carried out. All spectra were recorded at $25^{\circ} \mathrm{C}$ and with a spectral resolution of $1 \mathrm{~cm}^{-1}$. FT-IR spectra of solid state samples as $\mathrm{KBr}$ dispersions pressed disks, have been recorded in the $400-4000 \mathrm{~cm}^{-1}$ spectral region with a Perkin Elmer Spectrum RX I FT-IR spectrometer. 
Powder X-ray diffraction patterns have been collected in the 2-80 degree range using a Philips (PW1050/39 X Change) diffractometer provided of a copper anode $(\mathrm{Cu}, \mathrm{K} \alpha=1.5418 \AA)$.

Inclusion complexes were prepared accordingly to two different procedures, as explained below.

- Lyophilized complexes were prepared by mixing opportune volume of a MLT solution $(0,002 \mathrm{M})$ with a weighed quantity of CD. In order to speed up dissolution of the $\mathrm{CD}$, and particularly in the case of $\beta-C D$, the resulting initial dispersion deposed in an ultrasonic bath for 15 minutes. The resulting clear solution finally frozen and at last freeze dried with a Edward Modulyo apparatus.

- Crystalline complexes were prepared even in this case by mixing opportune volume of a MLT solution $(0,002 \mathrm{M})$ with weighed quantities of CD and the same ultrasonic treatment was used to speed up CD dissolution. The resulting clear solution was put in a dark desiccator, and finally dried for three days under vacuum in complete darkness, using a membrane vacuum pump Vacuubrand ME2C. Darkness is require to avoid MLT decomposition.

\section{Acknowledgments}

Financial support "Fondi Ricerca Scientifica" of the University of Palermo is gratefully acknowledged.

\section{References}

1. Reiter, R.J. News Physiol. Sci. 1991, 6, 223.

2. Morgan, P.J.; Williams, L.M. Experientia 1989, 45, 955.

3. Reiter, R.J; Carneiro, R.C.G.; OH, C.S. Horm. Metab. Res. 1997, 29, 343.

4. Tan, D.X.; Chen, L.D.; Poeggeler, B.; Manchester, L.C.; Reiter, R.J. Endocrinol. J. 1993, 1, 57.

5. Livrea, M.A.; Tesoriere, L.; D’Arpa, D.; Morreale, M. Free Rad. Biol. Med. 1997, 23, 706.

6. Marshall, K.A.; Reiter, R.J.; Poeggeler, B.; Aruoma, O.I.; Halliwell, B. Free Rad. Biol. Med. 1996, 21, 307.

7. Turjanski, A.G.; Leonik, F.; Estrin, D.A.; Rosestein, R.E.; Doctovich, F. J. Am. Chem. Soc. 2000, 122, 468.

8. Uppu, R.; Prior, W.A. J. Am. Chem. Soc. 1999, 121, 9738.

9. Lissoni, P.; Barni, S.; Brivio, F.; Rossini, F.; Fumagalli, L.; Ardizzoia, A.; Tancini, G. Oncology 1995, 52, 360.

10. Lissoni, P.; Meregalli, S.; Nosetto L.; Barni, S.; Tancini, G.; Fossati, V.; Mestroni, G. Oncology 1996, 53, 43. 
11. Barni, S.; Dissoni, P.; Cazzaniga, M.; Ardizzoia, A.; Meregalli, S.; Fossati, V.; Fumagalli, L.; Brivio, F.; Tancini, G. Oncology 1995, 52, 243.

12. Maestroni, G.J. Cancer Research 1994, 54, 2429.

13. Maurizi, C.P. Med. Hypotheses 1995, 45, 340.

14. Pappolla, M.A.; Reiter, R.J.; Bryant-Thomas, T.K. Curr. Med. Chem. 2003, 3, 233.

15. Abe, M.; Reiter, R.J.; Poeggeler, B. J. Pineal Res. 1994, 17, 94.

16. Flitter, W.D. British Medical Bulletin 1993, 49, 545.

17. Cardinali, D.P.; Ladiezesky, M.G.; Boggio, V.; Cutrera, R.A; Mautalen, C. J. Pineal Res. 2003, 34, 81 .

18. Cheung, T.F. J. Pineal Res. 2003, 34, 153.

19. Bongiorno, D.; Ceraulo, L.; Mele, A.; Panzeri, W.; Selva, A.; Turco Liveri, V. Carbohyd. Res. 2002, 337, 743.

20. Bongiorno, D.; Ceraulo, L.; Mele, A.; Panzeri, W.; Selva, A.; Turco Liveri, V. J. Mass. Spectrom. 2001, 36, 1189.

21. Zhang, C.; Tan, X.; Tan, H. Chin. Pat. Appl. 1998, CN 113169.

22. Santus, G.; Golzi, R.; Besana, G. International Pat. Appl. 1999, WO 9947175.

23. Baker, M.T.; Attala; M.N. U.S.. Pat. Appl. 2002, US 2002-78643 20020219.

24. Shida, C.S.; Castrucci, A.M.L.; Lamy-Freund, M.T. J. Pineal Res. 1994, 16, 198.

25. Bongiorno, D.; Ceraulo, L.; Ferrugia, M.; Filizzola, F.; Ruggirello, A.; Turco Liveri. V. ARKIVOC 2004, 5; 251

26. Szejtli, J. Chem. Rev. 1998, 98, 1743.

27. Uekama, K.; Hirayama, F.; Irie, T. Chem. Rev. 1998, 98, 2045.

28. Redenti, E.; Ventura, P.; Fronza, G.; Selva, A.; Rivara, S.; Plazi, P.V.; Mor, M. J. Pharm. Sci. 1999, 88, 599.

29. Fronza, G.; Mele, A.; Redenti, E.; Ventura, P.G. Org. Chem. 1996, 61, 909.

30. Lipkowitz, K.B.; Raghothama, S.; Yang, J. J. Am. Chem. Soc. 1992, 114, 1554.

31. Mauri, P.; Mele, A.; Panzeri, W.; Selva, A. Eur. J. Mass Spectrom. 2000, 6, 174.

32. Montassier, P.; Duchêne, D.; Poelmann, M.C. Int. Journ. Pharm. 1997, 153, 209.

33. Bongiorno, D.; Ceraulo, L.; Ferrugia, M.; Filizzola, F.; Ruggirello, A.; Turco Liveri V. J. Pineal Res. 2005, 37, 00 in press. 